\title{
USO DA FAUNA E FLORA POR COMUNIDADES QUILOMBOLAS DO ARQUIPÉLAGO DO MARAJÓ, PARÁ
}

\author{
FAUNA AND FLORA USES BY QUILOMBOLAS COMMUNITIES FROM \\ MARAJÓ ARCHIPELAGO, PARÁ
}

\author{
Regian Ferreira Sena ${ }^{1}$, Marcela Alvares Oliveira ${ }^{2}$, \\ Fernanda Carneiro Romagnoli ${ }^{3}$, Ana Paula Vitoria Costa-Rodrigues ${ }^{4 *}$
}

\begin{abstract}
Resumo:
O Brasil apresenta uma das maiores taxas de diversidade biológica e cultural do planeta. O conhecimento e uso de elementos da fauna e da flora por comunidades quilombolas são parte importante desta diversidade e demonstram a relevância social destes povos. Reconhecer e valorizar estes saberes é elemento relevante na luta pelos direitos quilombolas. Neste trabalho, objetivou-se registar as etnoespécies reconhecidas pelas comunidades quilombolas Bacabal, Boa Vista e Pau Furado, localizadas em Salvaterra, Pará, bem como as principais formas de uso destes recursos naturais. A pesquisa foi realizada em três locais: Bacabal, Boa Vista e Pau Furado, comunidades rurais do município de Salvaterra, arquipélago do Marajó, Pará, norte do Brasil. Foram entrevistadas 33 pessoas que mencionaram 141 etnoespécies distribuídas nas categorias medicinal, alimentícia, ornamental, artesanato, construção, ritual/religioso e lenha. As práticas da roça, caça, pesca e a criação de animais fazem parte do cotidiano dessas comunidades e garantem a subsistência das famílias. Essas atividades de manipulação dos recursos naturais são responsáveis por seu papel social, cultural e econômico, revelando a intrínseca relação que estas comunidades mantêm com os recursos locais.
\end{abstract}

Palavras-chave: Amazônia; Uso medicinal; Etnozoologia; Etnobotânica; Uso da biodiversidade. 


\begin{abstract}
:
Brazil has one of the highest rates of biological and cultural diversity of the planet. Fauna and flora uses and knowledge by quilombolas communities are important part of this diversity and demonstrates the social relevance of this people. Recognizing and valuing this knowledge is a relevant element in the fight for quilombola rights. This work aimed to record the ethnospecies recognized by the quilombola communities Bacabal, Boa Vista and Pau Furado, located in Salvaterra, Pará, as well as the main ways of using these natural resources. The research was carried out in three locations: Bacabal, Boa Vista and Pau Furado, rural communities in Salvaterra, Marajó archipelago, Pará, northern Brazil. Thirty-three people were interviewed who mentioned 141 ethnospecies distributed in medicinal, food, ornamental, handcraft, construction, ritual/religious and firewood categories. The practice of farming, hunting, fishing and raising animals are part of the daily life of these communities and guarantee the subsistence of families. Manipulation of natural resources are responsible for their social, cultural and economic role, revealing the intrinsic relationship that these communities have with local resources.
\end{abstract}

Keywords: Amazon; Medicinal use; Ethnozoology; Ethnobotany; Biodiversity use.

\title{
1. Introdução
}

O Brasil apresenta uma das maiores taxas de diversidade biológica e cultural do planeta. No país, existem mais de 500 terras indígenas reconhecidas pelo Estado e cerca de 3.386 comunidades quilombolas oficialmente certificadas (ARRUTI et al., 2020). Embora ainda sejam alvo de processos sociais excludentes, os descendentes de negros africanos fazem parte da diversidade social do Brasil e apresentam múltiplas realidades étnicas e culturais (SANTOS et al., 2012).

A luta das comunidades quilombolas no Brasil se sustenta, principalmente, na conquista da regularização de seus territórios. O reconhecimento territorial constitui elemento fundamental à garantia de sobrevivência material e cultural destes povos, aspecto que ganhou força com a Constituição de 1988 (SILVA, 2007; CARDOSO, 2013); além disso, é essencial para o reconhecimento da história massacrante do povo negro no Brasil e para o fortalecimento da luta por outros direitos.

No estado do Pará, existem 56 territórios quilombolas (http://www.iterpa.pa.gov.br/content/quilombolas-0). Povos quilombolas e indígenas constituem os grupos étnicos mais importantes na formação da sociedade do arquipélago do Marajó, embora historicamente invisibilizados (MARIN, 2009). O município de Salvaterra é o que possui maior área ocupada por terras quilombolas. Existem, ao todo, 15 comunidades, dentre elas: Bacabal, Boa Vista e Pau Furado (GOMES et al., 2018).

A relação entre povos quilombolas e territórios que ocupam consiste em uma complexa rede de saberes e práticas formada por meio de processos históricos oriundos de atividades desenvolvidas por seus ancestrais e também por atividades desempenhadas atualmente. Neste processo, a convivência, o uso e o manejo da biodiversidade emergem como ações cotidianas. Tais comunidades chegam a desenvolver mecanismos próprios de categorização de espécies, atribuindo-lhes nomes e 
estabelecendo dinâmicas de uso e conservação de espécies (ESCOBAR, 2005; DIEGUES e PEREIRA, 2010).

Os nomes, as formas de uso e os valores atribuídos às espécies variam de acordo com a localidade e com as pessoas envolvidas. Por este motivo, estudos que envolvam a compreensão dos mecanismos de classificação e a caracterização do manejo dos variados organismos são importantes para se refletir o tipo de relação que a sociedade pretende ter com a biodiversidade, podendo dar subsídio a planos de manejo e conservação mais eficazes (FRAZÃO-MOREIRA, 2001; LEFF, 2005).

O objetivo desse artigo foi registar as etnoespécies reconhecidas pelas comunidades quilombolas Bacabal, Boa Vista e Pau Furado, localizadas em Salvaterra, Pará, bem como as principais formas de uso destes recursos naturais.

\section{Material e Métodos}

\subsection{Caracterização das comunidades estudadas}

O município de Salvaterra localiza-se no norte do Estado do Pará a, aproximadamente, $91 \mathrm{~km}$ da capital Belém, no arquipélago do Marajó, na Ilha do Marajó. É constituído pelos distritos de Salvaterra (sede), Condeixa, Joanes, Jubim e Monsarás. Segundo estimativa do Instituto Brasileiro de Geografia e Estatística (IBGE, 2020), o município apresentava uma população de 24.075 pessoas distribuída em uma área de 918,563 km² em 2020 (www.ibge.gov.br).

Os negros africanos chegaram à Ilha do Marajó no final do século XVII na condição de escravos e exerceram trabalhos ligados à pecuária, atividade recém-introduzida na região. A escravidão e as péssimas condições de vida nas grandes fazendas impulsionaram diversas pessoas à fuga na tentativa de sobrevivência e resistência. Além disso, a pecuária tornou-se economicamente instável em todo o arquipélago do Marajó nos séculos XVII, XVIII e XIX, o que fez com que muitas fazendas fossem abandonadas por seus proprietários, que passaram a residir na capital, Belém. Com isto, quilombolas, indígenas e mestiços conseguiram ocupar terras abandonadas, receberam em doações ou as compraram, formando comunidades em diversos lugares, especialmente no município de Salvaterra (MARIN, 2009; CARDOSO, 2013; GOMES et al., 2018).

Atualmente, Salvaterra possui 15 comunidades rurais reconhecidas como quilombolas que ainda não possuem o título definitivo de seu território. Os residentes nestas comunidades vivem, principalmente, da agricultura, pesca, caça e extrativismo vegetal (GOMES et al., 2018). Entre elas estão as comunidades Bacabal, Boa Vista e Pau Furado, que localizam-se a uma distância em torno de 7 a $8 \mathrm{~km}$ do núcleo urbano de Salvaterra. Bacabal foi uma das primeiras comunidades quilombolas de Salvaterra a iniciar o processo de reconhecimento de seu território, ainda não concluído. Em Bacabal residem 60 famílias que mantêm seu sustento a partir do cultivo e venda de mandioca, macaxeira, abacaxi, além da pesca, programas de transferência de renda do governo e aposentadorias.

Na comunidade Boa Vista residem 97 famílias, porém, este número pode estar em crescimento, pois em 2016 a comunidade recebeu o programa do Governo Federal "Minha casa, minha vida", que permitiu a construção de novas moradias. Com isso, 
muitas famílias polinucleadas passaram a ser mononucleadas. A principal fonte de renda é a plantação de macaxeira, da qual são extraídas a farinha comum, a farinha de tapioca, o tucupi, a goma (utilizada no preparo do tacacá) e a maniva (folha da mandioca, ingrediente principal da maniçoba). Tacacá e maniçoba são pratos típicos da culinária paraense. Todos os extratos da mandioca citados são elementos fundamentais na alimentação paraense e contribuem fortemente para a segurança alimentar de muitas famílias.

A comunidade Pau Furado faz fronteira com Bacabal, compartilhando elementos da flora e da fauna. Conta com 16 famílias que sobrevivem principalmente da produção coletiva de farinha de mandioca. Algumas famílias praticam a caça e a pesca.

\subsection{Coleta e análise dos dados}

A proposta da pesquisa foi apresentada às lideranças locais. A coleta de dados ocorreu entre abril e setembro de 2016, com total de 33 entrevistas, sendo 10 na comunidade Bacabal, 11 na comunidade Pau Furado e 12 na comunidade Boa Vista. Foram convidadas a participar da pesquisa pessoas maiores de 18 anos com, no mínimo, cinco anos de residência na comunidade, conforme Miranda e Hanazaki (2008). O primeiro entrevistado em cada comunidade foi indicado pela liderança local. Os demais entrevistados foram selecionados com base no método Snowball, onde um morador indicava outro (ALBUQUERQUE et al., 2010). A indicação ocorria com base no modo de vida do entrevistado, com enfoque naquelas pessoas que produziam roça, caçavam, pescavam e que eram reconhecidas como detentoras de conhecimento acerca dos usos múltiplos de recursos naturais, incluindo os usos alimentício, medicinal e ornamental. Todos os participantes tiveram assegurado seu direito ao anonimato e a possibilidade de não integrar a pesquisa, caso não fosse de seu interesse.

A todos os entrevistados foram aplicados questionários com perguntas sobre o perfil socioeconômico e entrevistas semiestruturadas a respeito da relação com os recursos naturais. Os questionários abordaram perguntas como tempo de residência na comunidade, localidade de origem, autodeclaração de cor, ocupação, se faz uso da linguagem escrita e o nível de educação formal. As entrevistas abordaram questões referentes às etnoespécies de fauna e flora e a seus usos pelas comunidades. O registro dos dados foi feito por meio de anotação manual associada à gravação de áudio e ao uso de diário de campo com base em Bernard (2006).

Os dados foram analisados de forma quali-quantitativa e apresentados em tabelas conforme Posey (1986). Foi feito o registro da frequência absoluta e relativa de citações de uso de cada etnoespécie por categoria. Para a listagem das espécies da flora, foram criadas sete categorias étnicas sobre o uso destas: "alimentação", "medicinal", "construção", "artesanal", "ornamental", "lenha" e "ritual/simbólico". Para as espécies da fauna, foram utilizadas as mesmas categorias, com exceção de "lenha" (BERNARD, 2006). Também foram identificadas as estruturas utilizadas de cada etnoespécie. Essas categorias foram criadas para melhor compreender e nomear as etnoespécies indicadas pelos entrevistados. 


\section{Resultados}

\subsection{Aspectos socioeconômicos e culturais das populações estudadas}

A idade dos entrevistados variou entre 18 e 72 anos. A maior parte dos entrevistados afirmou trabalhar por conta própria (80\% em Bacabal; 58,33\% em Boa Vista; e 90,90\% em Pau Furado). As atividades nas comunidades - roça, caça e pesca - são desenvolvidas tanto por homens quanto por mulheres e envolvem quase todos os integrantes da família, com exceção das crianças. É comum adolescentes praticarem a caça assim como a pesca na comunidade Pau Furado. A principal forma de subsistência dessas famílias quilombolas está pautada no cultivo da roça, correspondendo a 85,72\%, 57,15\% e 90\% nas comunidades Bacabal, Boa Vista e Pau Furado, respectivamente (Tabela 1).

Tabela 1: Características socioeconômicas gerais das 33 famílias entrevistadas.

\begin{tabular}{|c|c|c|c|c|}
\hline \multicolumn{2}{|c|}{ Dados socioculturais e econômicos } & \multirow{2}{*}{$\begin{array}{l}\text { Bacabal (\%) } \\
30\end{array}$} & \multirow{2}{*}{$\begin{array}{l}\text { Boa Vista (\%) } \\
25\end{array}$} & \multirow{2}{*}{$\begin{array}{l}\text { Pau Furado (\%) } \\
20\end{array}$} \\
\hline & Masculino & & & \\
\hline Gerneto & Feminino & 70 & 75 & 80 \\
\hline \multirow{6}{*}{ Idade } & $18-29$ & 50 & 25 & 27,28 \\
\hline & $30-39$ & 10 & 25 & 36,36 \\
\hline & $40-49$ & 10 & 8,33 & 18,18 \\
\hline & $50-59$ & 10 & 16,67 & 18,18 \\
\hline & $60-69$ & 20 & 8,33 & - \\
\hline & 70 ou mais & - & 16,67 & - \\
\hline \multirow{5}{*}{ Autodeclaração de cor } & Branca & - & - & - \\
\hline & Parda & 20 & 58,33 & 45,45 \\
\hline & Preta & 80 & 41,67 & 54,55 \\
\hline & Indígena & - & - & - \\
\hline & Amarela & - & - & - \\
\hline \multirow{2}{*}{ Origem } & Local & 60 & 50 & 82 \\
\hline & Externa & 40 & 50 & 18 \\
\hline \multirow{2}{*}{ Uso de linguagem escrita } & Sim & 100 & 83,33 & 100 \\
\hline & Não & - & 16,67 & - \\
\hline \multirow{5}{*}{ Educação formal } & Fund. Incompleto & 50 & 60 & 54,55 \\
\hline & Fund. Completo & - & - & 9,09 \\
\hline & Méd. Incompleto & 50 & 20 & 18,18 \\
\hline & Méd. Completo & - & 10 & 18,18 \\
\hline & Ens. Superior & - & 10 & - \\
\hline
\end{tabular}

Fonte: os autores.

\subsection{Usos múltiplos da fauna e da flora}

Os resultados permitiram identificar 141 etnoespécies da flora e fauna citadas pelos moradores das comunidades quilombolas Bacabal, Boa Vista e Pau Furado, incorporadas a sete categorias de uso: alimentação, medicinal, construção, artesanato, ornamental, lenha e ritual/simbólico. As plantas obtiveram maiores citações $(n=50$; $\mathrm{n}=26 ; \mathrm{n}=36$, nas comunidades Bacabal, Boa Vista e Pau Furado, respectivamente), 
correspondendo a 79,44\% das citações, possuindo diversos fins para subsistência dessas famílias.

\subsubsection{Usos de espécies da fauna}

A prática da caça nas comunidades estudadas é destinada, sobretudo, ao consumo familiar, sendo realizada, predominantemente, por homens, adolescentes menores de 18 anos. Os entrevistados citaram nove espécies que ocorrem na região e que são utilizadas para alimentação, uso medicinal e uso ornamental (couro dos animais). Dentre as etnoespécies mais citadas, está o tatu - família Dasypodidae (n=13); a cutia família Dasyproctidae ( $\mathrm{n}=7)$ e o quati - família Procyonidae $(\mathrm{n}=8)$.

A categoria "uso medicinal" (Tabela 2) foi a mais citada. Os moradores das comunidades utilizam, sobretudo, a gordura dos animais, como o tatu e a paca, para tratar diversas enfermidades, como inflamações em geral (dor de garganta, reumatismo), cãibra, asma e derrame. Alguns moradores de Pau Furado citaram o fel (vesícula biliar agregada ao fígado) do tatu e da paca como remédio para inflamação e derrame, somando com a indicação do fel da paca para combater o câncer de próstata, na comunidade de Boa Vista.

Tabela 2. Famílias e etnoespécies da fauna citadas pelos entrevistados. Categoria de uso segundo os domínios culturais dos entrevistados: alimentar (Al); Medicinal (Me); Ornamental (Or).

\begin{tabular}{lllllll}
\hline Família & Etonespécie & Bacabal & Boa Vista & Pau Furado & Total & Domínio de uso \\
\hline Boidae & Jiboia & - & 1 & - & 1 & $\mathrm{Me}$ \\
Cervidae & Veado & - & 3 & 4 & 6 & $\mathrm{Al} ; \mathrm{Me}$ \\
Iguanidae & Iguana & 2 & 2 & - & 4 & $\mathrm{Al} ; \mathrm{Me}$ \\
Cuniculidae & Paca & - & 2 & 4 & 6 & $\mathrm{Al} ; \mathrm{Me}$ \\
Dasypodidae & Tatu & 2 & 3 & 8 & 13 & $\mathrm{Al} ; \mathrm{Me}$ \\
Dasyproctidae & Cutia & - & 2 & 5 & 7 & $\mathrm{Al}$ \\
Procyonidae & Quati & 5 & - & 3 & 8 & $\mathrm{Al} ; \mathrm{Me} ; \mathrm{Or}$ \\
Viperidae & Cascavel & - & 2 & - & 2 & $\mathrm{Me}$ \\
\hline
\end{tabular}

Fonte: os autores.

Assim como a caça, a pesca é uma das formas de subsistência dos moradores das três comunidades (16,66\%). Os moradores citaram o uso do peixe somente na categoria alimentação, sendo preparada de forma cozida, frita ou assada. Para esses pescadores, o peixe, além de servir de base para a alimentação de suas famílias, constitui uma fonte de renda e subsistência, já que o alimento é facilmente comercializado para parte da população de Salvaterra. (Tabela 3). 
Tabela 3. Famílias e etnoespécies de peixes citados pelos moradores das comunidades de Bacabal, Boa Vista e Pau Furado, Salvaterra-PA.

\begin{tabular}{llllll}
\hline Família & Etonespécie & Bacabal & Boa Vista & Pau Furado & Total \\
\hline Anostomidae & Aracu & - & 2 & - & 2 \\
Characidae & Piranha & - & 2 & - & 2 \\
Cichlidae & Acará & 1 & 2 & 1 & 4 \\
Doradidae & Tucunaré & - & - & 1 & 1 \\
Erithrynidae & Bacu & 1 & - & 1 & 2 \\
\hline
\end{tabular}

Fonte: os autores.

Além dos animais de caça e de pesca, os entrevistados citaram cinco espécies de animais de criação adquiridos por compra, como o pato, ou pela caça, como o quati. Geralmente essas famílias criam o animal até este se tornar adulto o suficiente para o abate, conforme necessidade da família.

Na categoria medicinal foi citado, por exemplo, o uso da fumaça da queima do chifre do boi perto de crianças para afastar piolho e da banha da galinha e do quati, para tratar inflamação muscular. Na categoria ornamental, o chifre do boi e o couro do quati foram citados como artigos de decoração. Na categoria artesanal, o chifre do boi foi mencionado para uso na fabricação de berrantes e para ritual/religioso, onde também a fumaça da sua queima serve para afastar entidades sobrenaturais ou espirituais indesejadas (caboco) (Tabela 4).

Tabela 4. Famílias e etnoespécies de animais de criação citadas pelas famílias das comunidades de Bacabal, Boa Vista e Pau Furado, Salvaterra-PA. Categoria de uso: Alimentar (Al); Medicinal (Me); Ornamental (Or); Artesanal (Ar); Ritual/religiosos (Ri).

\begin{tabular}{lllllll}
\hline Família & Etonespécie & Bacabal & Boa Vista & Pau Furado & Total & Categoria de uso \\
\hline Anatidae & Pato & 3 & - & - & 3 & $\mathrm{Al}$ \\
Bovidae & Boi & 3 & - & - & 3 & $\mathrm{Al} ; \mathrm{Me} ; \mathrm{Or} ; \mathrm{Ar} ; \mathrm{Ri}$ \\
Phasianidae & Galinha & 4 & 5 & 4 & 13 & $\mathrm{Al} ; \mathrm{Me}$ \\
Procyonidae & Quati & 4 & - & 4 & 8 & $\mathrm{Al} ; \mathrm{Me} ;$ Or \\
Suidae & Porco & 3 & 4 & 4 & 11 & $\mathrm{Al}$ \\
\hline
\end{tabular}

Fonte: os autores.

3.2.2 Recursos florísticos e suas categorias de uso: plantas de uso alimentício, medicinal, ritual/religioso elenha

As três categorias de uso mais citadas foram "uso alimentício" ( $\mathrm{n}=29)$, "uso medicinal" ( $n=21)$ e "lenha" ( $n=6)$ em Bacabal; "uso medicinal" ( $n=15)$, "uso alimentício" ( $n=8)$ e "ritual/religioso" ( $n=7$ ) em Boa Vista; e "uso medicinal" ( $n=16)$, "ritual/religioso" (n=12) e "uso alimentício" (n=10) em Pau Furado. As classificações de uso dos recursos florísticos foram definidas de acordo com as circunstâncias de cada comunidade bem como suas práticas em diferentes ocasiões. 
A categoria alimentícia foi expressiva nas três comunidades estudadas (Bacabal, Boa Vista e Pau Furado). Muitas plantas foram citadas como temperos de alimentos. Também foram citadas plantas frutíferas que servem para a alimentação. Entretanto, o dado mais expressivo está relacionado ao uso da mandioca e da macaxeira, amplamente citadas nas três comunidades, evidenciando que são uma das principais formas de alimentação das famílias da região (Tabela 5). Em Bacabal, Boa Vista e Pau Furado, as famílias usam a mandioca sobretudo para produção da farinha, elemento fundamental da alimentação na região norte do Brasil.

Tabela 5. Lista de etnoespécies da categoria "uso alimentício", por número de citações dos entrevistados das comunidades quilombolas Bacabal, Boa Vista e Pau Furado, Salvaterra/PA.

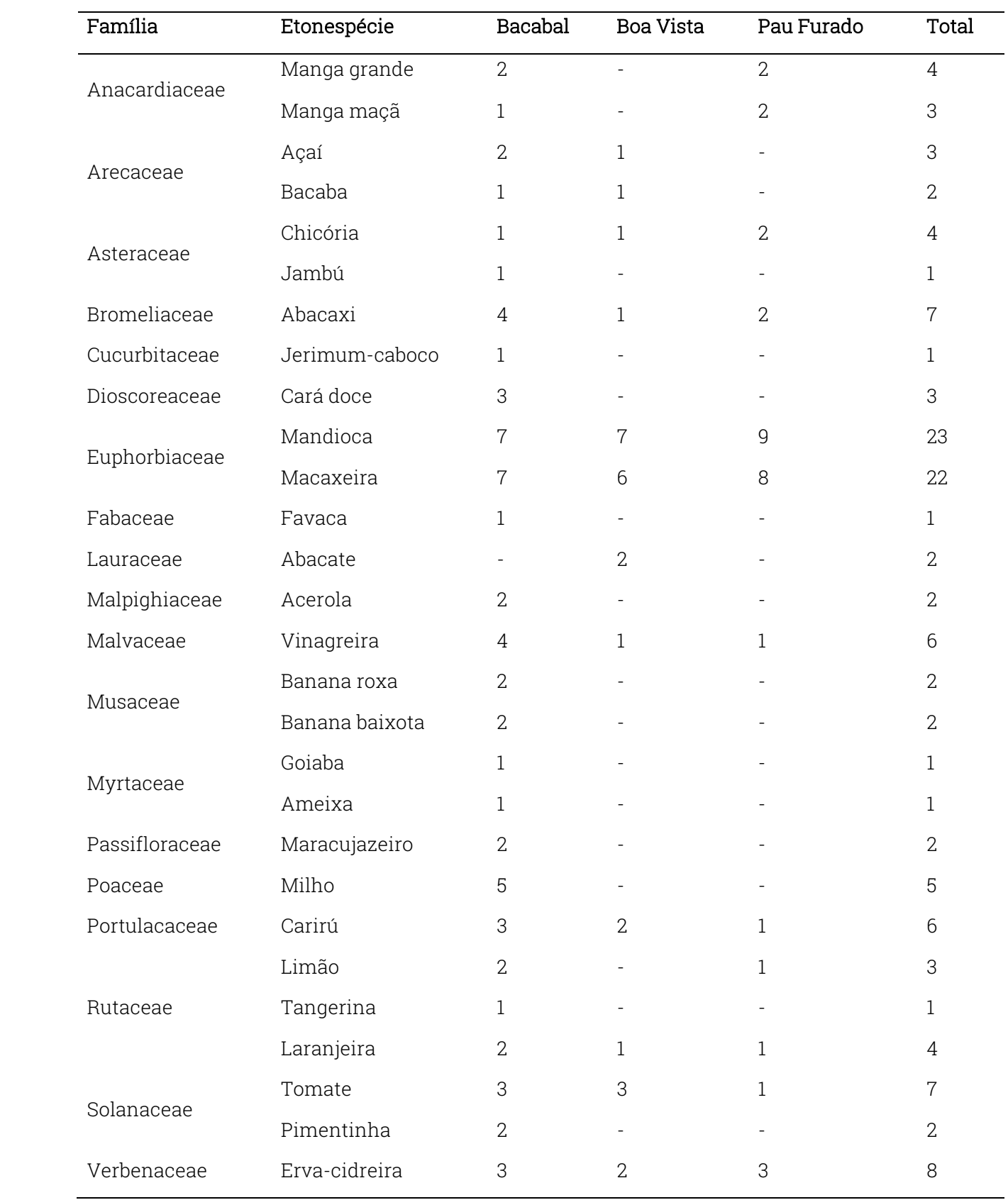

Fonte: os autores.

Em relação à categoria medicinal, foram reunidas informações de 40 etnoespécies 
pertencentes a 23 famílias, sendo mais representativas as Amaranthaceae, Asteraceae, Fabaceae, Lamiaceae (Tabela 6).

A forma de preparo mais citada pelos entrevistados das três comunidades foi o chá, seja da folha, da casca ou da raiz, e as indicações foram bem variadas, incluindo desde dor de cabeça e gripe a doenças como tuberculose e derrame. Por meio da correlação de dados, foi possível verificar que os moradores, sobretudo os mais idosos, possuem maior conhecimento sobre como os remédios caseiros feitos a partir dessas plantas podem agir sobre o organismo.

Tabela 6. Lista de etnoespécies da categoria medicinal citadas pelas famílias das comunidades quilombolas de Bacabal, Boa Vista e Pau Furado, Salvaterra/PA.

\begin{tabular}{|c|c|c|c|c|c|c|}
\hline Família & Etonespécie & Bacabal & Boa Vista & Pau Furado & Total & Indicações \\
\hline \multirow{3}{*}{ Acanthaceae } & For-sangue & 2 & - & - & 2 & Anemia \\
\hline & Anador & - & - & 1 & 1 & Dor geral \\
\hline & Corrente & 3 & - & 1 & 4 & Barriga inchada \\
\hline \multirow[t]{2}{*}{ Amaranthaceae } & Ampicilna & 1 & - & - & 1 & Infecção e inflamação \\
\hline & Meracilina & - & 2 & - & 2 & Anti-inflamatório \\
\hline \multirow[t]{3}{*}{ Arecaceae } & Pupunha & - & 1 & - & 1 & Inflamação para nascida \\
\hline & Cipó de sucuriju & 2 & - & - & 2 & Artrite \\
\hline & Japana branca & - & - & 3 & 3 & Derrame \\
\hline \multirow[t]{2}{*}{ Asteraceae } & $\begin{array}{l}\text { Japana } \\
\text { madeira }\end{array}$ & - & - & 3 & 3 & Dor geral \\
\hline & Japana roxo & - & - & 3 & 3 & Dor de cabeça \\
\hline Bignoniaceae & Paríri & 1 & - & 1 & 2 & Anemia \\
\hline Brassicaceae & Couve-flor & - & 1 & - & 1 & Combate o AVC \\
\hline Caricaceae & Mamão-macho & - & - & 1 & 1 & Diarreia \\
\hline \multirow{2}{*}{ Crassulaceae } & Desinflama & 2 & - & - & 2 & Curar ferimento \\
\hline & Pirarucu & - & 2 & 2 & 4 & Inflamação \\
\hline Cyperaceae & Batatinha piará & 1 & - & - & 1 & Vômito e disenteria \\
\hline \multirow{2}{*}{ Euphorbiaceae } & Coramina & 3 & - & - & 3 & Dores no coração \\
\hline & Sacaca & 1 & - & - & 1 & Dores no fígado \\
\hline \multirow{3}{*}{ Fabaceae } & Jucá & 2 & - & 2 & 4 & Febre \\
\hline & Verônica & - & 1 & - & 1 & Anemia \\
\hline & Babatimão & - & 2 & - & 2 & Inflamação \\
\hline Gramineae & Capim-marinho & - & 2 & - & 2 & Acalma o bebê \\
\hline Iridaceae & Marupazinho & - & - & 1 & 1 & Diarreia \\
\hline Liliaceae & Babosa & 4 & - & - & 4 & $\begin{array}{l}\text { Gastrite e tuberculose; fortalece } \\
\text { os cabelos }\end{array}$ \\
\hline \multirow{3}{*}{ Lamiaceae } & Oriza & 1 & - & 1 & 2 & Derrame \\
\hline & Favação & - & 1 & - & 1 & Dor de cabeça \\
\hline & Hortelã & - & - & 3 & 3 & Gripe \\
\hline \multirow{2}{*}{ Malvaceae } & Vinagre roxo & 1 & - & - & 1 & Dor de Cabeça \\
\hline & Algodoeiro & - & - & 1 & 1 & Tosse; catarro \\
\hline
\end{tabular}




\begin{tabular}{|c|c|c|c|c|c|c|}
\hline Oxalidaceae & Trevo-roxo & - & - & 1 & 1 & Dor de cólica e ouvido \\
\hline Portulacaceae & Amor-crescido & - & 3 & - & 3 & Dor no estômago \\
\hline Rosaceae & Rosa todo ano & - & - & 2 & 2 & Problema no coração \\
\hline Rubiaceae & Quina & 1 & - & - & 1 & Dor no intestino \\
\hline \multirow{2}{*}{ Rutaceae } & Arruda & - & 1 & - & 1 & Dor de cabeça \\
\hline & Limão & - & - & 2 & 2 & Febre \\
\hline Verbenaceae & Erva-cidreira & - & 3 & - & 3 & Faz o bebê dormir \\
\hline \multirow{2}{*}{ Zingiberaceae } & Gengibre & 2 & - & - & 2 & Dor nos dentes; tosse \\
\hline & Canaficha & 1 & - & - & 1 & Infecção urinária \\
\hline
\end{tabular}

Fonte: os autores

A categoria de uso "ritual/religioso" está entre as três mais citadas pelos entrevistados das comunidades Boa Vista e Pau Furado, assim como a categoria "lenha" na comunidade Bacabal (Tabela 7). É muito comum a utilização de plantas para benzer crianças, afastar mal olhado, proteger a casa etc. Essa prática é feita especialmente por pessoas mais velhas. Segundo os moradores, esse costume aos poucos vai perdendo espaço nas novas gerações, todavia, ainda há quem utilize esse exercício como forma de proteção espiritual. A cosmologia presente no intrínseco comunitário reforça a espiritualidade deixada por seus antepassados, os anos de fugas e de adaptação às formas florística e faunística da região.

Tabela 7. Lista de estnoespécies citadas pelas famílias das comunidades Bacabal, Boa Vista e Pau Furado, Salvaterra/PA. Categoria de uso: Ritual/religioso (Ri); Lenha (Le).

\begin{tabular}{|c|c|c|c|c|c|c|}
\hline Família & Etnoespécie & Bacabal & $\begin{array}{l}\text { Boa } \\
\text { Vista }\end{array}$ & Pau Furado & $\begin{array}{l}\text { Total } \\
\text { citações }\end{array}$ & $\begin{array}{l}\text { Categoria de } \\
\text { uso }\end{array}$ \\
\hline Acanthaceae & Abre caminho & - & - & 5 & 5 & $\mathrm{Ri}$ \\
\hline Anacardiaceae & Mangueira & 2 & - & 2 & 4 & Le \\
\hline \multirow{4}{*}{ Araceae } & Sombra do mundo & 3 & - & 3 & 6 & $\mathrm{Ri}$ \\
\hline & Rio Negro & - & 2 & 3 & 5 & $\mathrm{Ri}$ \\
\hline & $\begin{array}{l}\text { Comigo ninguém } \\
\text { pode }\end{array}$ & 2 & - & 2 & 4 & $\mathrm{Ri}$ \\
\hline & Tracuá & - & - & 2 & 2 & $\mathrm{Ri}$ \\
\hline Asteraceae & Japana madeira & - & - & 3 & 3 & $\mathrm{Ri}$ \\
\hline Clusiaceae & Bacurizeiro & 2 & - & 2 & 4 & Le \\
\hline Commelinaceae & Dinheiro em penca & - & - & 4 & 4 & $\mathrm{Ri}$ \\
\hline Equisetaceae & Chicote de índio & - & - & 1 & 1 & $\mathrm{Ri}$ \\
\hline Euphorbiaceae & Pião roxo & - & 3 & - & 3 & $\mathrm{Ri}$ \\
\hline Lamiaceae & Favacão & - & - & 1 & 1 & $\mathrm{Ri}$ \\
\hline \multirow{3}{*}{ Liliaceae } & Alho & - & 3 & - & 3 & $\mathrm{Ri}$ \\
\hline & Espada de São Jorge & 2 & 3 & 3 & 8 & $\mathrm{Ri}$ \\
\hline & $\begin{array}{l}\text { Espada de Joana } \\
\text { Darc }\end{array}$ & - & 3 & 3 & 6 & $\mathrm{Ri}$ \\
\hline Malpighiaceae & Murucizeiro & 2 & 1 & 1 & 4 & Le \\
\hline Malvaceae & Algodoeiro & 1 & - & - & 1 & Le \\
\hline
\end{tabular}




\begin{tabular}{lllllll} 
& Cupuaçu & - & - & 2 & 2 & Le \\
Phytolacaceae & Mucuracaá & - & 2 & 2 & 4 & Ri \\
Rosaceae & Marmeleiro & 1 & - & - & 1 & Le \\
\hline
\end{tabular}

Fonte: os autores.

Na comunidade Pau Furado foi registrado o maior número de etnoespécies com fins rituais/religiosos, destacando-se as estnoespécies "comigo ninguém pode" (Famílias Araceae), indicada para mal olhado e inveja; "abre caminho" (Família Acanthaceae), indicada para dar sorte e afastar espíritos; "espada de Joana Dar'c" e "espada de São Jorge" (família Liliaceae), indicadas para proteger a casa contra inveja. O uso de plantas com finalidade espiritual está ligado à busca por segurança e bem-estar individual, familiar e comunitário.

A categoria "lenha" foi expressiva principalmente na comunidade Bacabal. Plantas como o muricizeiro, mangueira e bacurizeiro são empregados na fabricação do carvão, tornando-se uma das principais formas de fazer fogo para cozinhar o alimento. A prática de fabricação do carvão foi constatada nas três comunidades, sendo a produção in loco a principal forma de obtenção de lenha. Esta prática também configura-se como uma forma de subsistência, uma vez que muitas famílias vendem o carvão, ajudando a compor a renda familiar. Em geral, plantas utilizadas para a produção do carvão também servem para construir barracas, casas, mesas, dentre outros objetos, fortalecendo a ideia de múltiplas finalidades de uso desses recursos florísticos.

\section{Discussão}

Os entrevistados das três comunidades são predominantemente pessoas pretas, na faixa etária de 18 a 39 anos, perfil similar ao encontrado em outras comunidades quilombolas (BEZERRA et al., 2013; FREITAS et al., 2018). Em todas as comunidades foi observado que a maioria dos entrevistados vivem de forma marital, considerando-se casados, pois vivem com seus companheiros na mesma casa, compartilhando os afazeres domésticos e trabalhistas da família. As mulheres foram as maiores informantes do estudo, visto que a maioria dessas trabalha em suas próprias residências com os serviços domésticos e pequenas plantações nos quintais de suas casas, tendo maior disponibilidade para participar da pesquisa. De acordo com o Centro de Estudos e Defesa do Negro no Pará - CEDENPA - (2016), as mulheres quilombolas do município de Salvaterra estão à frente de muitas associações e promovem encontros pela luta por seus direitos perante a sociedade, tornando-se pilares fundamentais das comunidades.

Quanto à localidade de origem, a maioria dos entrevistados afirmou que sempre residiu no mesmo local, desde o seu nascimento (60\%), o que provavelmente agregou maior confiabilidade às respostas. Além disso, os moradores originários de outros locais (40\%) vieram de comunidades próximas que também sofrem influência da cultura regional quilombola. Silva et al (2013), no estudo realizado na comunidade quilombola do Curiarú-AP, notaram que 92,83\% dos entrevistados residiam no local há mais de 10 anos e frisam que esse é um fator fundamental para a integração socioeconômica e cultural, pois nesse período as tradições locais já estão bem ancoradas no íntimo do indivíduo. Quase todos os entrevistados fazem uso da linguagem escrita (sabem ler e escrever), 
com exceção de aproximadamente 16\% dos participantes da comunidade Boa Vista. Com relação à educação formal (formação escolar), quase todos chegaram a concluir o Ensino Médio.

As atividades nas comunidades - caça, pesca, plantio de roça e criação de animais são desenvolvidas tanto por homens quanto por mulheres. Uma pesquisa realizada com populações quilombolas do Vale do Ribeira-SP mostrou que a roça é a principal forma de subsistência das populações locais, haja vista que é praticada pela maioria das famílias com percentual de 93\%, sendo ainda a mandioca uma das principais etnoespécies cultivadas para alimentar a população (PEDROSO-JUNIOR et al., 2008).

Além da mandioca e da macaxeira, nas comunidades de Salvaterra, o abacaxi (família Bromeliaceae) também é cultivado em larga escala, utilizado sobretudo para a comercialização intermunicipal, garantindo o sustento familiar. De acordo com Relatório Analítico do Território do Marajó (2012), os municípios Cachoeira do Arari e Salvaterra são os maiores produtores de abacaxi do Marajó. Salvaterra possui a segunda maior produção de abacaxi do Pará, tendo sido responsável por 95\% dos frutos consumidos na capital Belém em 2020, além de estar entre as três cidades que mais produzem abacaxi no Brasil. A fala de um morador da comunidade Boa Vista retrata a importância do abacaxi para esta comunidade: "A gente trabalha com a roça [...] tudo é queimado, mas é a forma que nós da zona rural temos como sobrevivência, principalmente a roça de abacaxi"(Entrevistado de Boa Vista).

A caça desempenha papel importante na manutenção da subsistência de diversos grupos sociais que vivem em áreas onde a natureza e seus recursos ainda são abundantes. Os recursos faunísticos são utilizados dependendo do grupo e de sua cultura em diversas finalidades como alimentação, comércio, criação doméstica, produção artesanal, uso medicinal, mágico religioso, entre outros (OLIVEIRA e CALOURO, 2019; BELFORT et al., 2020; RAMOS et al., 2020; SILVA e BARROS, 2020). A prática da caça desempenhada por adolescentes menores de 18 anos também foi notada nos estudos de Figueiredo e Barros (2015), em comunidades que mantêm laços com o ambiente, onde comumente jovens com essa faixa-etária são os responsáveis por tal aquisição do alimento. A gordura se destacou como um dos principais produtos zooterápicos utilizados, conforme também observado em outros estudos (MARTINEZ et al., 2013; CASTILLO e LADIO, 2019; MISHRA et al., 2020), podendo esse padrão estar relacionado com a atividade de caça (COSTA-NETO, 1999) e a facilidade de obtenção do produto. Outro aspecto importante é a versatilidade de tratamentos atribuídos a uma mesma parte, bem como partes diferentes de um animal, destacando a potencialidade farmacológica inexplorada associada à fauna amazônica.

Os povos da floresta possuem relações específicas com o meio em que vivem e até mesmo com o tempo, determinadas por suas características ancestrais em consonância com aspectos da atualidade. Em muitos pontos essas relações diferenciam-se da dinâmica estabelecida pela cultura urbano-industrial. Um exemplo está no ato de se alimentar, que constitui uma necessidade básica para qualquer humano e, concomitantemente, uma atividade cultural, permeada por crenças, tabus, distinções e cerimônias (PEDRAZA, 2004). Para os povos da floresta, alimentar-se não representa somente $\mathrm{o}$ ato de incorporar elementos nutritivos ao organismo, mas também a relação que se dá entre as pessoas (como amigos e familiares), promove convívio, atua na manutenção cultural e da coesão familiar/comunitária. Exemplos 
característicos são a partilha e a dinâmica coletiva de preparo de alimentos, relevantes quando se fala em carne de caça (FIGUEIREDO e BARROS, 2016; NUNES et al., 2019)

De modo geral, os peixes possuem inegável importância tanto em termos ecológicos quanto em termos sociais (para uso comercial e alimentar) (BARROS, 2012). Os peixes acará e traíra presentes nas três comunidades estão contidos nas ordens de animais aquáticos de maior distribuição no Brasil juntamente com piranha, bagre, piabas, entre outros (ROSA e LIMA, 2008). Barros (2012) constata a presença de diversos peixes utilizados na alimentação e no comércio, dentre estes está a traíra, tucunaré, piranha, assim como outros animais encontrados tipicamente na região norte do país.

Para Costa-Neto (1999; 2000), as comunidades que mantêm laços com o ambiente, em sua maioria, agregam animais, sejam eles silvestres ou não, como forma de garantir sua subsistência perante alguma dificuldade. Animais como boi, galinha e porco estão entre os animais de criação de maior destaque para o alimento e outras formas de uso, como o medicinal. Pinto (2012) destaca como animal doméstico de criação a galinha, pelo fácil modo como se adapta a qualquer condição de vida das famílias, sendo um dos principais animais usados para na alimentação da comunidade de Ponta Grossa/PB.

A mandioca é a planta base da alimentação da população amazônica. Durante o processo de colonização do Brasil, esta planta foi o principal alimento dos brasileiros, e até hoje alimenta muitos povos das regiões tropicais do todo o mundo, desempenhando então um papel tanto socioeconômico, quanto histórico (CASTRO, 1965). A utilização da mandioca e da macaxeira por parte das famílias quilombolas de Salvaterra é uma das principais formas de sustento do grupo comunitário, pois além da venda esse recurso também subsidia a alimentação diária dessas famílias.

Costa (2011), ao estudar a comunidade quilombola Boa Vista do Itá, Santa Isabel/PA, verificou que a mandioca e os produtos extraídos dela estão presentes em quase todas as refeições das famílias. É utilizada como a principal forma de subsistência, importante não só para a alimentação, mas também para a economia. O mesmo foi constatado nas comunidades estudadas em Salvaterra. O cultivo da mandioca é altamente disseminado em todo território brasileiro e relacionado à agricultura familiar, sendo a principal fonte de renda e item da alimentação (FARALDO et al., 2000; SILVA e MURRIETA, 2014). Por essas razões não é incomum que moradores de pequenas comunidades em diferentes partes no Brasil façam uso dessa cultura.

Assim como a categoria alimentícia, a categoria medicinal também foi destaque, chamando atenção para as 40 etnoespécies citadas das famílias Amaranthaceae, Asteraceae, Fabaceae e Lamiaceae. Franco (2005), no trabalho desenvolvido no quilombo Olho D'Água dos Pires, município de Esperantina/PI, constatou que de 57 famílias identificadas, grande parte das etnoespécies pertencem às famílias Asteraceae, Lamiaceae, além da Arecaceae e Euphorbiaceae. Resultado semelhante foi encontrado em uma comunidade rural do semiárido da Paraíba por Santos (2009), onde se destacaram também entre a categoria medicinal as famílias Asteraceae, Lamiaceae e Fabaceae. Miranda e Hanazaki (2008) identificaram as mesmas famílias como as mais abundantes em comunidade da Ilha do Cardoso (SP) e de Santa Catarina. Possivelmente, a similaridade entre as diferentes localidades do Brasil pode estar relacionada com a ampla distribuição geográfica dessas famílias, sua adaptação ao clima do Brasil e amplo conhecimento popular disseminado. 
A maioria dessas famílias vegetais apresenta maiores registros em trabalhos com levantamentos de plantas medicinais no Brasil. Isso pode estar relacionado ao fato de estas famílias serem ricas em compostos fitoquímicos, que são geralmente empregadas em medicamentos (LORENZI e MATOS, 2008).

A espiritualidade das comunidades quilombolas de Salvaterra manifesta-se, em grande parte, por meio do uso dos recursos florísticos. São muitas as finalidades místicas que as plantas representam para esses grupos. Maciel e Guarim-Neto (2006) verificaram que 87 etnoespécies distribuídas em 30 famílias na categoria "medicinal" possuíam importância místico-cultural, sendo as famílias Lamiaceae, Rutaceae e Araceae como as mais abundantes, utilizadas, sobretudo, para banho com o intuito de afastar espíritos, mal olhado, inveja, dentre outros males.

Com o estudo da cultura quilombola evidencia-se uma série de métodos de uso da fauna e da flora relacionados à espiritualidade. Este aspecto é de suma importância para a afirmação e manutenção das características de um povo. Souza et al. (2012), em estudo sobre plantas utilizadas em fitomagia citam 29 estnoespécies que servem de proteção contra mau olhado, inveja, entidades sobrenaturais, apontam a etnoespécie "espada de São Jorge", como uma das plantas principais usadas em momentos de rituais, assim como observado nas comunidades Bacabal, Boa Vista e Pau Furado. De acordo com os moradores, essa planta é indispensável aos rituais pelo alto grau de "proteção" espiritual que oferece.

\section{Conclusões}

As comunidades quilombolas Bacabal, Boa Vista e Pau Furado de Salvaterra/PA possuem relevantes práticas de uso dos recursos naturais, responsáveis pela manutenção física, social, cultural e econômica dessas comunidades, abrangendo desde aspectos alimentares a rituais religiosos. A grande variedade de etnoespécies de plantas para uso alimentar, destacando as pertencentes à família Euphorbiaceae e de formas de uso medicinal de animais, tais como os atribuídos à gordura dos tatus, por exemplo, mostra a intrínseca relação que estas comunidades têm com os recursos locais, incluindo a espiritualidade que engloba essas relações. As comunidades necessitam destas espécies para sua subsistência e manutenção da cultura local. Como se trata de práticas de grupos representativos de toda uma cultura regional, manter estes recursos é importante para alimentar a história e cultura marajoara, além de garantir a possibilidade de uso para as populações urbanas. Portanto, é imprescindível que se conheça o repertório de conhecimentos e práticas que essas comunidades mantêm em relação à natureza para formular políticas públicas que valorizem os aspectos sociais, culturais, econômicos e sobretudo ambiental dessas populações.

Limitações metodológicas, como as dificuldades de acesso aos principais detentores destes conhecimentos que, por vezes não se encontram em casa ou não têm tempo para participar da pesquisa, podem refletir em parte dos resultados encontrados, sendo interessante, sempre que possível, associar as entrevistas a uma abordagem etnográfica, incluindo pesquisa participante. Assim, as informações obtidas neste trabalho abrem espaço a novas abordagens metodológicas e novos enfoques, especialmente relacionados às formas de transmissão de conhecimentos entre gerações e formas de obtenção dos recursos naturais. 


\section{Agradecimentos}

A todos os moradores das comunidades quilombolas Bacabal, Boa Vista e Pau Furado. A Universidade Estadual do Pará. Aos revisores anônimos pelas contribuições para a melhoria do artigo.

\section{Referências -}

ALBUQUERQUE, U. P.; LUCENA, R. F. P.; LINS-NETO, E. M. F. Seleção dos participantes da pesquisa. In: ALBUQUERQUE, U. P.; LUCENA, R. F. P.; CUNHA, L. V. (Org.). Métodos e técnicas na pesquisa etnobiológica e etnoecológica. Recife: NUPEEA, 2010. p. 83-106.

ARRUTI, J. M.; CRUZ, C.; PEREIRA, A.; SATORI, J.; SOUSA, C. J.; GUSMÃO, H. N. B.; BERTOLOZZI, T. B. O impacto da COVID-19 sobre as comunidades quilombolas. São Paulo, 2021. Disponível em: < https://cebrap.org.br/wpcontent/uploads/2021/01/Informativo-6-O-impacto-da-Covid-19-sobre-ascomunidades-quilombolas.pdf>. Acesso em: 03 jun. 2021.

BARROS, F. B. Etnoecologia da pesca na Reserva Extrativista Riozinho do Anfrísio Terra do Meio Amazônia, Brasil. Revista Amazônica, Belém, v. 4, n. 2, p. 286-312, 2012.

BELFORT, M. J. S.; BARBOSA, G. S.; SILVA, C. P.; OliveIRA, M. A. Perception of subsistence hunters in Lower Madeira on the impact of the Santo Antônio Hydroelectric Power Plant. Revista Brasileira de Ciências da Amazônia, Rolim de Moura, v. 9, n. 3, p. 16-25, 2020.

BERNARD, H. R. Research methods in anthropology: qualitative and quantitative approaches. 4. ed. New York: Altamira Press, 2006. 821 p.

BEZERRA, V. M.; ANDRADE, A. C. S.; CÉSAR, C. C.; CAIAFFA, W. T. Comunidades quilombolas de Vitória da Conquista, Bahia, Brasil: hipertensão arterial e fatores associados. Caderno de Saúde Pública, Rio de Janeiro, v. 29, n. 9, p. 1889-902, 2013.

CARDOSO, L. F. C. Reconhecimento e organização política quilombola na luta por território na Ilha do Marajó (PA). Cronos, Natal, v. 14, n. 2, p. 93-107, 2013.

CASTILLO, L.; LADIO, A. H. Zootherapy and rural livestock farmers in semiarid Patagonia: the transfer of animal aptitudes for health. Ethnobiology and Conservation, João Pessoa, v. 8, n. 2019, p. 2, 2019.

CASTRO, J. Geografia da fome. São Paulo: Brasiliense, 1965.

CENTRO DE ESTUDOS E DEFESA DO NEGRO NO PARÁ - CEDENPA. Negritude e equidade social. Belém, 2016. Disponível em: <http://www.cedenpa.org.br/>. Acesso em: 10 out. 2016 .

COSTA, M. S. Mandioca é comida de quilombola? Representações e práticas alimentares em uma comunidade quilombola da Amazônia brasileira. Revista Amazônica, Belém, v. 3, n. 2, p. 408-428, 2011. 
COSTA-NETO, E. M. Recursos animais utilizados na medicina tradicional dos índios Pankararé que habitam no nordeste do Estado da Bahia, Brasil. Actualidades Biológicas, Montenegro, v. 21, n. 70, p. 69-70, 1999.

COSTA-NETO, E. M. Conhecimento e usos tradicionais de recursos faunísticos por uma comunidade Afro-brasileira. Interciência, Caracas, v. 25, n. 9, p. 423-431, 2000.

DIEGUES, A. C.; PEREIRA, B. E. Conhecimento de populações tradicionais como possibilidade de conservação da natureza: uma reflexão sobre a perspectiva da etnoconservação. Desenvolvimento e Meio Ambiente, Paraná, v. 22, p. 37-50, 2010.

ESCOBAR, A. O lugar da natureza e a natureza do lugar: globalização ou pósdesenvolvimento. In. LANDER, E. (Org.). A colonialidade do saber: eurocentrismo e ciências sociais. Buenos Aires: CLASCO, 2005. P. 69-86.

FARALDO, M. I. F.; SILVA, R. M. D.; ANDO, A.; MARTINS, P. S. Variabilidade genética de etnovariedades de mandioca em regiões geográficas do Brasil. Scientia Agricola, Piracicaba, v. 57, n. 3, p. 499-505, 2000.

FIGUEIREDO, R. A.; BARROS, F. B. A comida que vem da mata: conhecimentos tradicionais e práticas culturais de caçadores na Reserva Extrativista Ipaú-Analzinho. Fragmentos de Cultura, Belém, v. 25, n. 2, p. 193-212, 2015.

FIGUEIREDO, R. A.; BARROS, F. B. Caçar, preparar e comer o 'bicho do mato': práticas alimentares entre os quilombolas na Reserva Extrativista Ipaú-Anilzinho (Pará). Boletim do Museu Paraense Emílio Goeldi. Ciências Humanas, Belém, v.11, n. 3, p. 691$713,2016$.

FRANCO, E. Á. A diversidade etnobotânica no quilombo Olho D'água dos Pires, Esperantina, Piauí, Brasil. 2005. Dissertação (Mestrado em Desenvolvimento e meio Ambiente) - Universidade Federal do Piauí, Teresina.

FRAZÃO-MOREIRA, A. As Classificações botânicas Nalu (Guiné-Bissau): consensos e variabilidades. Etnográfica, Lisboa, v. 1, p. 131-155, 2001.

FREITAS, I. A.; RODRIgUES, I. L. A.; DA SILVA, I. F. S.; NOGUEIRA, L. M. V. Perfil sociodemográfico e epidemiológico de uma comunidade quilombola na Amazônia Brasileira. Revista Cuidarte, Bucaramanga, v. 9, n. 2, p. 2187-200, 2018.

GOMES, D.L.; SCHMITZ, H.; BRINGEL, F.O. Identidade e mobilização quilombola na Amazônia marajoara. Boletim Goiano de Geografia, Goiânia, v. 38, n.3, p. 591-618. 2018.

INSTITUTO BRASILEIRO DE GEOGRAFIA E ESTATÍSTICA - IBGE. Cidades: Salvaterra 2021. Disponível em:<http://http://www.Cidades.Ibge.gov.br/xtras/perfil.php? lang=\&codmun $=150$ 630\&search=para|salvaterra $>$. Acesso em: 24 mai. 2021.

LEFF, E. Saber Ambiental. 4. ed. Petrópolis: Vozes, 2005. 494 p.

LORENZI, H.; MATOS, F. J. A. Plantas medicinais no Brasil: nativas e exóticas. Nova Odessa: Instituto Plantarum, 2008. 564 p.

MACIEL, M. R. A.; GUARIM-NETO, G. Um olhar sobre as benzedeiras de Juruema (Mato Grosso, Brasil) e as plantas usadas para benzer e curar. Boletim do Museu Paraense Emílio Goeldi Ciências Humanas, Belém, v. 1, n. 3, p. 61-77, 2006. 
MARIN, R. E.A. Quilombolas na Ilha do Marajó: território e organização política. In: GODOI, E.P.; MENEZES, M.A.; MARIN, R.E.A. (Orgs). Diversidade do campesinato: expressões e categorias. Construções identitárias e sociabilidades. Ed. UNESP. v.1, n.1, p.209-227, 2009.

MARTÍNEZ, G. J. Use of fauna in the traditional medicine of native Toba (qom) from the Argentine Gran Chaco region: an ethnozoological and conservationist approach. Ethnobiology and Conservation, João Pessoa, v. 2, n. 213, p. 2, 2013.

MIRANDA, T. M.; HANAZAKI, N. Conhecimento e uso de vegetais de restinga por comunidades da Ilhas do Cardoso (SP) e de Santa Catarina (SC), Brasil. Acta Botânica Brasileira, Belo Horizonte, v. 22, n. 1, p. 203-215, 2008.

MISHRA, B.; AKHILA, M. V.; THOMAS, A.; BENNY, B.; ASSAINAR, H. Formulated therapeutic products of animal fats and oils: future prospects of zootherapy. International Journal of Pharmaceutical Investigation v. 10, n. 2, p. 112-116, 2020.

NUNES, A. V.; Guariento, R. D.; Santos, B. A.; Fischer, E. Wild meat sharing among nonindigenous people in the southwestern Amazon. Behavioral Ecology and Sociobiology, Berlim, v. 73, n. 2, p. 26, 2019.

OLIVEIRA, M. A.; CALOURO, A. M. Hunting agreements as a strategy for the conservation of species: the case of the Cazumbá-Iracema Extractive Reserve, state of Acre, Brazil. Oecologia Australis, Rio de Janeiro, v. 23, n. 2, p. 357-366, 2019.

PEDROSO-JUNIOR, N. N.; MURRIETA, R. S.; TAQUEDA, C. S.; NAVAZINAS, N. D.; RUIVO, A. P.; BERNARD, D. V.; NEVES, W. A. A caça e a roça: Socioeconômica, demografia e agricultura em populações quilombolas do Vale do Ribeira, São Paulo, Brasil. Boletim do Museu Paraense Emílio Goeldi Ciências Humanas, Belém, v. 3, n. 2, p. 227-252, 2008.

PINTO, M. F. Caracterização socioambiental e uso de animas por comunidades tradicionais do litoral do Estado do Ceará. 2012. Dissertação (Mestrado em Desenvolvimento e Meio Ambiente) - Universidade Federal da Paraíba, João Pessoa.

POSEY, D.A. Introdução a Etnobiologia: teoria e prática. In: RIBEIRO, D. (Org.). Suma Etnológica Brasileira. Petrópolis: Vozes, 1986. p. 15-26.

RAMOS, C. G. S.; SANTOS, R. B.; SANTOS, R. W. C.; OLIVEIRA, M. A. Hunting in a community of waste pickers of recyclable materials in Rondônia, Brazil. Revista Brasileira de Ciências da Amazônia, Rolim de Moura, v. 9, n. 3, p. 4-15, 2020.

RELATÓRIO ANALÍTICO DO TERRITÓRIO DO MARAJÓ. Belém: Universidade Federal do Pará, 2012. 79 p. Disponível em: http://sit.mda.gov.br/download/ra/ral29.pdf. Acesso em: 04 jun. 2016.

ROSA, R. S; LIMA, F. C. T. Os peixes brasileiros ameaçados de extinção. In: MACHADO, Â. B.; DRUMMOND, G. M.; PAGLIA, A. P. Livro vermelho da fauna brasileira ameaçada de extinção volume II. Brasília: MMA, 2008. p. 1-278.

SANTOS, S. L. D. Animais e plantas utilizadas como medicinais por uma comunidade rural do semi-árido da Paraíba, nordeste do Brasil. 2009. Dissertação (Mestrado em Ciência e Tecnologia Ambiental) - Universidade Estadual da Paraíba, Campina Grande. 
SANTOS, S. P.; CARDOSO, L. F.; VALENTE, O. R. A Lógica da Ação Coletiva e a Busca pela Cidadania: uma análise de associações quilombolas de Salvaterra-Marajó/PA. In. III ENCONTRO DA REGIÃO NORTE DA SOCIEDADE BRASILEIRA DE SOCIOLOGIA: AMAZÔNIA E SOCIOLOGIA: FRONTEIRAS DO SÉCULO XXI, 2012, Manaus. Relatório final... Manaus: Universidade Federal do Amazonas, 2012. 18 p.

SILVA, P. S. Política públicas e mediação na comunidade de Quilombos de Casca, Mostardas, RS. 2007. Dissertação (Mestrado em Desenvolvimento Rural) - Universidade Federal do Rio Grande do Sul, Porto Alegre.

SILVA, R. B.; FREITAS, J. C.; SANTOS, J. U.; SOUTO, R. N. Caracterização agroecológica e socioeconômica dos moradores da comunidade quilombola do Cariaú, Macapá-AP, Brasil. Biota Amazônica, Macapá, v. 3, n. 3, p. 113-138, 2013.

SILVA, H. A. D.; MURRIETA, R. S. S. Mandioca, a rainha do Brasil? Ascensão e queda da Manihot esculenta no estado de São Paulo. Boletim do Museu Paraense Emílio Goeldi. Ciências Humanas, Belém, v. 9, n. 1, p. 37-60, 2014.

SILVA, E. S.; BARROS, F. B. A caça e os caçadores Tapirapé da Aldeia Tapi'itãwa. Tellus, Campo Grande, v. 20, n. 42, p. 217-247, 2020.

SOUZA, R. R.; DANTAS, I. C.; SOBRINHA, L. C.; CHAVES, T. P. Plantas utilizadas em fitomagia na cidade de Limoeiro. Revista de Biologia e Farmácia, João Pessoa, v. 7, n. 2, p. 92-101, 2012. 